\title{
Apatinib as post second-line therapy in EGFR wild-type and ALK-negative advanced lung adenocarcinoma
}

This article was published in the following Dove Press journal:

OncoTargets and Therapy

18 January 2017

Number of times this article has been viewed

\author{
Shen-Cun Fang ${ }^{1,2}$ \\ Hai-Tao Zhang' \\ Ying-Ming Zhang' \\ Wei-Ping $\mathrm{Xie}^{2}$ \\ 'Department of Respiratory Medicine \\ Center, Nanjing Chest Hospital, \\ ${ }^{2}$ Department of Respiratory and \\ Critical Care Medicine, The First \\ Affiliated Hospital of Nanjing Medical \\ University, Nanjing, Jiangsu, People's \\ Republic of China
}

\begin{abstract}
In the absence of a driver mutation, chemotherapy is the standard treatment option as first- and second-line therapy for advanced non-small-cell lung cancer (NSCLC). Though a large number of patients are suitable for post second-line therapies, the quality and quantity of the available drugs in this setting is poor. Apatinib, a small molecule vascular endothelial growth factor receptor-2 (VEGFR-2) tyrosine kinase inhibitor, is a first-generation oral antiangiogenesis drug approved in the People's Republic of China for use as a subsequent line of treatment for advanced gastric cancer. Herein, we report three cases of advanced NSCLC with epidermal growth factor receptor wild-type and anaplastic lymphoma kinase-negative status, wherein the patients showed partial response to apatinib. Moreover, the three patients have achieved a progression-free survival of 2.8, 5.8, and 6 months, respectively. The main toxicities were hypertension, proteinuria, and hand-foot syndrome. Apatinib may provide an additional option for the treatment of advanced NSCLC, especially for advanced lung adenocarcinoma without a driver mutation.
\end{abstract}

Keywords: non-small-cell lung cancer, angiogenesis, apatinib, VEGFR-2

\section{Introduction}

Non-small-cell lung cancer (NSCLC) is the leading cause of cancer death worldwide. ${ }^{1}$ Epidermal growth factor receptor (EGFR) tyrosine kinase inhibitors (TKIs) and anaplastic lymphoma kinase (ALK) inhibitors are currently recommended as the best treatment option for patients harboring EGFR mutations and ALK rearrangements, respectively. ${ }^{2,3}$ Checkpoint blockade blockers have also demonstrated promising responses in NSCLC patients with PD-L1 expression. ${ }^{4}$ For the majority of NSCLC patients without a genetic driver mutation, platinum-based doublet chemotherapy is the standard treatment option for advanced NSCLC. ${ }^{5,6}$ However, most patients experience disease progression within 6 months from first-line therapy and require salvage therapy. ${ }^{7}$ Docetaxel and pemetrexed are considered standard second-line therapies based on several randomized controlled trials. ${ }^{8,9}$ Despite the fact that a considerable proportion of patients $(26 \%-38 \%)$ are suitable for post second-line therapies, ${ }^{10}$ the quality and quantity of the available drugs in this setting is poor.

Apatinib, a small molecule vascular endothelial growth factor receptor-2 (VEGFR-2) TKI, is a first-generation oral antiangiogenesis drug approved in the People's Republic of China for use as a subsequent line of treatment for advanced gastric cancer. However, there is no report focusing on its efficacy and safety in patients with NSCLC. Herein, we report three cases of advanced NSCLC with EGFR wild-type and ALK-negative status, wherein the patients showed partial response (PR) to apatinib. 


\section{Case presentation}

Patient I, a 70-year-old nonsmoking female, was admitted with a 1-month history of cough and chest pain. A chest computed tomography (CT) scan revealed a large mass in the right lower lobe with a small amount of right pleural effusion and pericardial effusion. Brain magnetic resonance imaging indicated the presence of multiple intracranial metastatic tumors. No metastasis was observed on abdominal ultrasound examination and whole body bone scan. CT-guided percutaneous right pulmonary biopsy indicated lung adenocarcinoma. No gene mutations were detected in EGFR or ALK examination. The diagnosis was right lung adenocarcinoma with multiple intracranial metastases (Table 1). Doublet chemotherapy of cisplatin and pemetrexed was administered for two cycles; the therapeutic evaluation was progressive disease (PD). Docetaxel was prescribed as second-line chemotherapy. Reevaluation imaging after 2 months demonstrated an increase in the size of pulmonary metastases, with multiple metastases in the left lung and left malignant pleural effusion. The patient experienced severe dyspnea and had a performance status (PS) of 4 . Then, she received apatinib treatment $(500 \mathrm{mg} /$ day) and PR was detected after 2 weeks of treatment (Figure 1).

Table I Baseline characteristics of patients

\begin{tabular}{|c|c|c|c|}
\hline Characteristics & Case I & Case 2 & Case 3 \\
\hline Age (years) & 70 & 42 & 66 \\
\hline Sex & Female & Female & Male \\
\hline Smoking & No & No & Light smoker \\
\hline Pathologic type & Adenocarcinoma & Adenocarcinoma & Adenocarcinoma \\
\hline \multicolumn{4}{|l|}{ Gene type } \\
\hline EGFR & Wild-type & Wild-type & Wild-type \\
\hline ALK & Negative & Negative & Negative \\
\hline Stage & IV (cT4N2MIb) & IV (cT4NIMIa) & IV (cT4NIMIa) \\
\hline \multicolumn{4}{|c|}{ Therapy (response) } \\
\hline First line & $\begin{array}{l}\text { Pemetrexed/ } \\
\text { cisplatin (PR) }\end{array}$ & $\begin{array}{l}\text { Pemetrexed/ } \\
\text { cisplatin (PR) }\end{array}$ & $\begin{array}{l}\text { Pemetrexed/ } \\
\text { cisplatin (SD) }\end{array}$ \\
\hline Second line & Docetaxel (PD) & $\begin{array}{l}\text { Docetaxel/ } \\
\text { carboplatin (SD) }\end{array}$ & $\begin{array}{l}\text { Docetaxel/ } \\
\text { carboplatin (PD) }\end{array}$ \\
\hline Third line & Apatinib (PR) & $\begin{array}{l}\text { Gemcitabine/ } \\
\text { nedaplatin (PD) }\end{array}$ & Apatinib (PR) \\
\hline Fourth line & & Apatinib (PR) & \\
\hline \multicolumn{4}{|l|}{ CEA $(\mu \mathrm{g} / \mathrm{mL})$} \\
\hline Pre-apatinib & 85 & 28 & 56 \\
\hline Post-apatinib & 35 & 16 & 20 \\
\hline PFS (months) & 2.8 & 5.8 & 6 \\
\hline \multicolumn{4}{|l|}{ Adverse events } \\
\hline Hypertension & Grade 2 & Grade 3 & Grade 3 \\
\hline $\begin{array}{l}\text { Hand-foot } \\
\text { syndrome }\end{array}$ & & Grade 2 & \\
\hline Proteinuria & Grade I & & \\
\hline
\end{tabular}

Abbreviations: ALK, anaplastic lymphoma kinase; CEA, carcinoembryonic antigen; EGFR, epidermal growth factor receptor; PD, progressive disease; PFS, progressionfree survival; PR, partial response; SD, stable disease.
In addition, dyspnea diminished within 4 days and the PS of the patient improved from 4 to 2 . Progression-free survival (PFS) after apatinib treatment was 2.8 months. The main toxicities were proteinuria and hypertension (Table 1).

Patient II, a 42-year-old female who is a never-smoker, was admitted with a 2-month history of cough. Chest CT showed that there was a lesion at the right upper lobe, with multiple metastases in the right lung and right pleural effusion. Adenocarcinoma cells were found in the pleural effusion. Cellular immunohistochemistry studies confirmed primary adenocarcinoma of the lung. The patient was diagnosed with stage IV non-small-cell lung adenocarcinoma. The pleural effusion specimen from this patient was tested for EGFR and ALK. The findings showed that EGFR mutations and ALK were negative (Table 1). The patient was administered six cycles of pemetrexed/cisplatin from August 2014; the therapeutic evaluation was PR. The patient was further given six cycles of pemetrexed maintenance therapy from February 2015. As second-line therapy, carboplatin and docetaxel were prescribed for four cycles from September 2015; the therapeutic evaluation was stable disease (SD). Chemotherapy of "gemcitabine and nedaplatin" was administered for one cycle from January 2016 as a third-line treatment. Re-evaluation chest $\mathrm{CT}$ demonstrated an increase in the size of pulmonary metastases. The patient developed a poor general condition. She received apatinib treatment $(500 \mathrm{mg} /$ day $)$ from March 2016 and showed PR after 1 month (Figure 2). She has achieved a PFS of 5.8 months. The toxicities the patient experienced were mainly hand-foot skin reaction and hypertension, which were well managed (Table 1).

Patient III, a 66-year-old man who is a light smoker, was admitted with a 1-month history of cough. Chest CT showed a right upper lobe mass of about $2 \mathrm{~cm}$, with multiple metastases in the lower lobe of right lung and right pleural effusion. Adenocarcinoma cells were found in the pleural effusion. Cellular immunohistochemistry confirmed primary adenocarcinoma of the lung. Gene detection showed that the ALK rearrangement was negative and EGFR was wildtype (Table 1). As first-line chemotherapy, the regimen of "pemetrexed plus cisplatin" was initiated for four cycles from May 2015. The therapeutic evaluation was SD. Repeat evaluation imaging (December 2015) demonstrated that the right pulmonary lesions increased rapidly. Chemotherapy consisting of "docetaxel plus carboplatin" was prescribed as a second-line treatment. Following two cycles of chemotherapy, the patient developed worsening dyspnea and had a PS of 3. Re-evaluation showed disease progression in the right lung lesions. Therefore, treatment with apatinib $(500 \mathrm{mg} / \mathrm{day})$ 

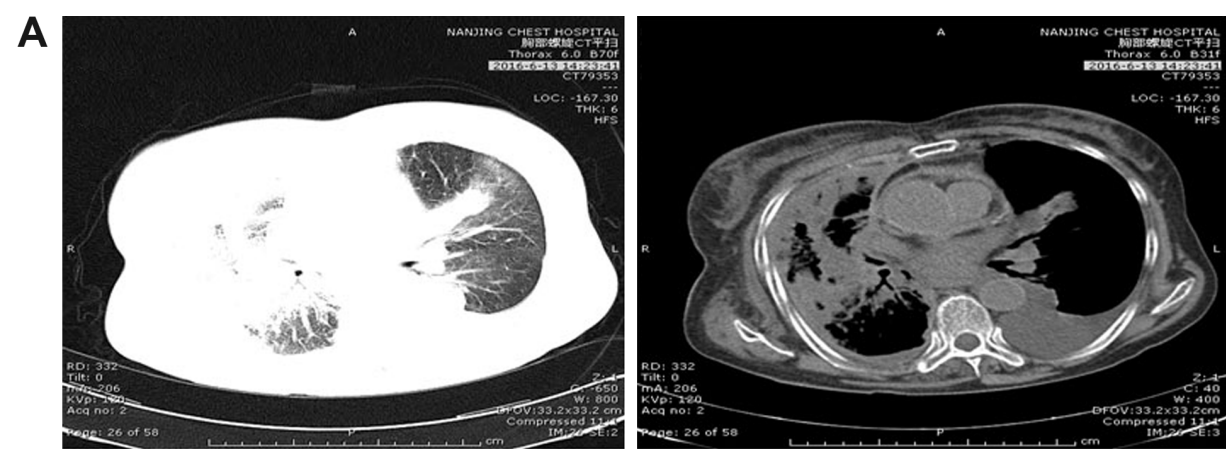

B
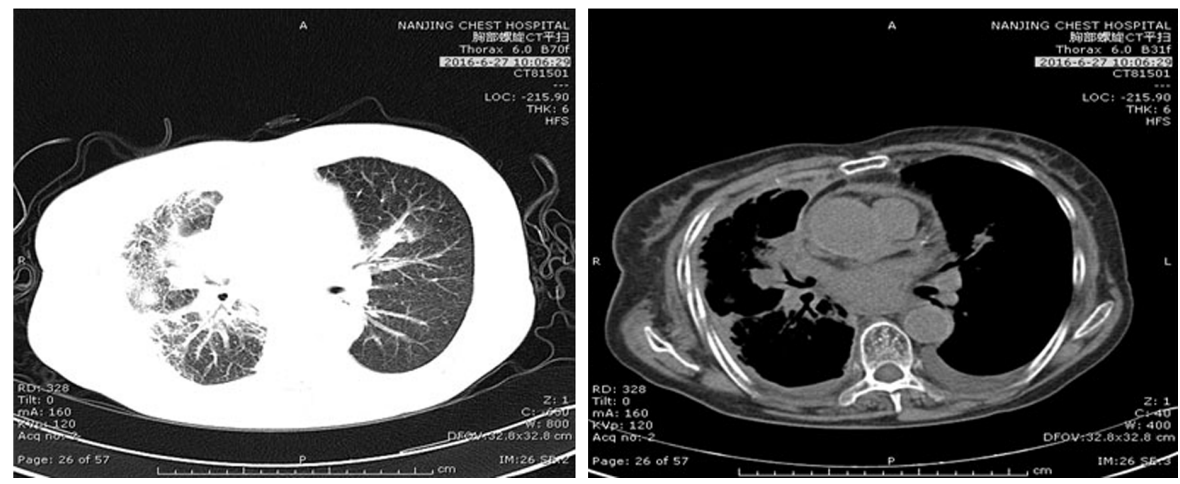

Figure I Patient I: Computed tomography shows the mass in the right lung with left lung metastasis and pleural effusion (A) before apatinib treatment and (B) after apatinib treatment was given for 2 weeks.
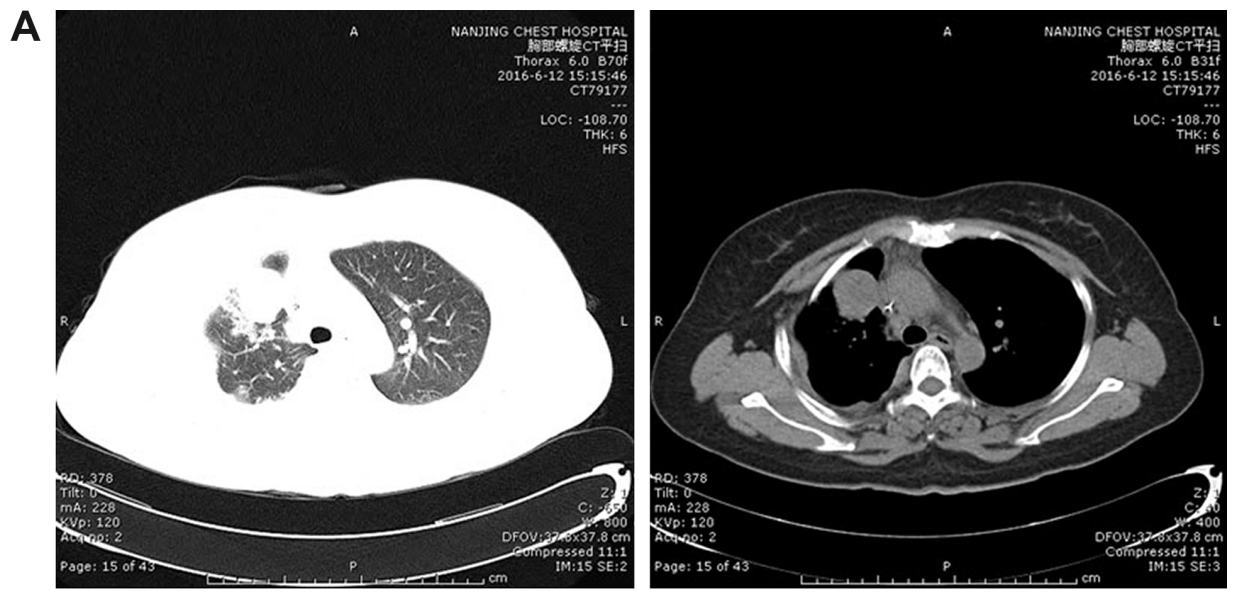

B
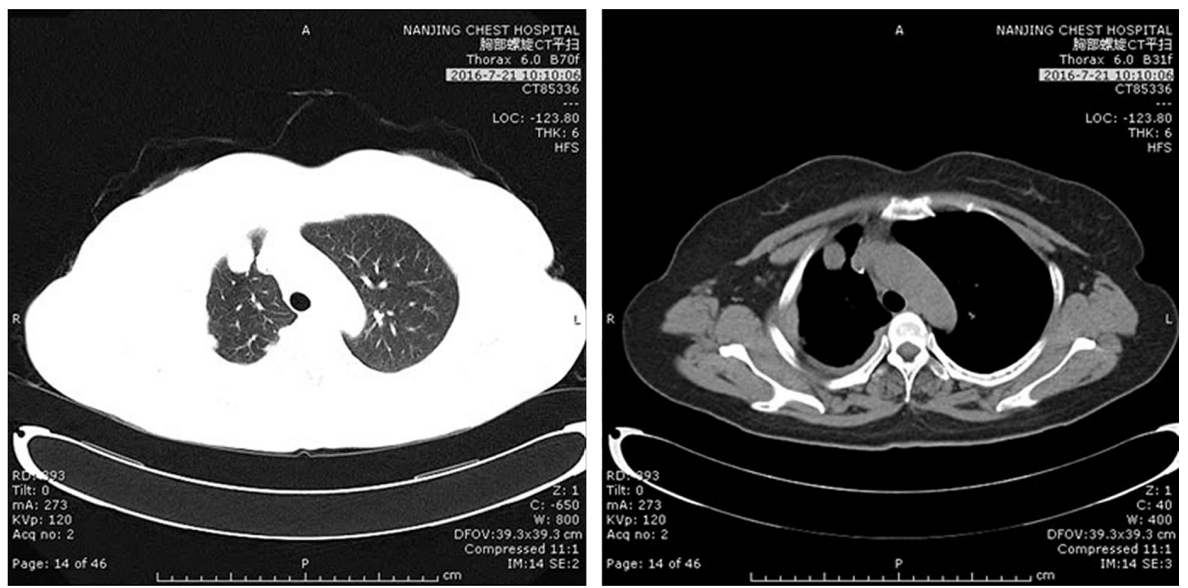

Figure 2 Patient II: Computed tomography shows the mass in the right lung (A) before apatinib treatment and (B) after apatinib treatment was given for I month. 

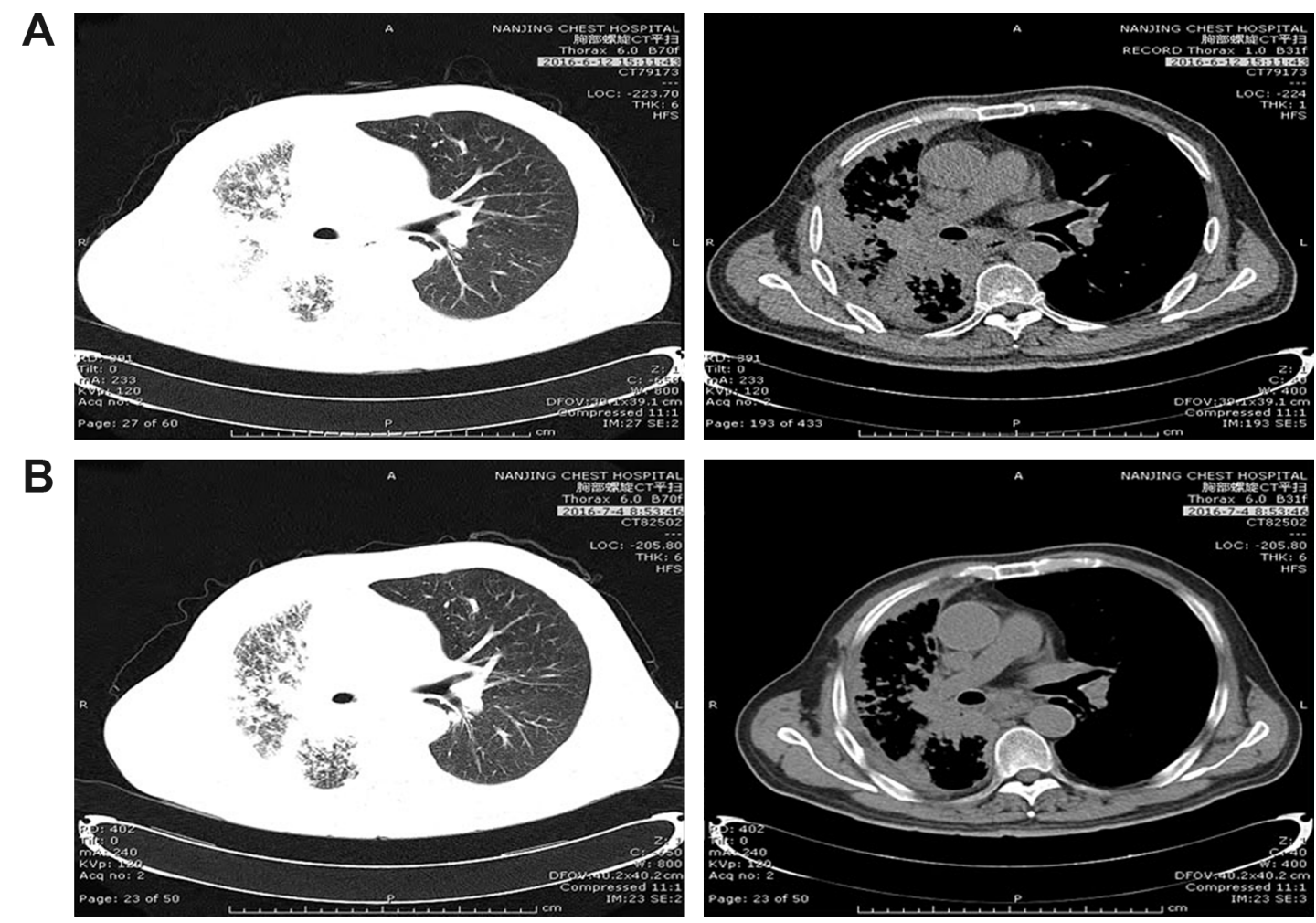

Figure 3 Patient III: Computed tomography shows the mass in the right lung (A) before apatinib treatment and (B) after apatinib treatment was given for 3 weeks.

was administrated as a third-line treatment. After 3 weeks of treatment with apatinib, PR was detected in the right lung lesion (Figure 3) and PS of the case improved from 3 to 1. The patient's PFS has increased to 6 months after taking apatinib. The only toxicity was grade 3 hypertension, which was well relieved by antihypertensive treatment without dose adjustment (Table 1).

\section{Discussion}

Tumor angiogenesis plays a critical role in tumor growth, development, and metastasis. Serum VEGF activates VEGFR-2, inducing a cascade of different signaling pathways, promoting endothelial cell migration and proliferation necessary for angiogenesis. Given its central role in cancer angiogenic process, several agents targeting VEGF/VEGFR-2 axis have been developed for inhibition of tumor angiogenesis and have shown encouraging efficacy in several tumor types.

However, blockage of VEGF pathway in advanced NSCLC by either adding antiangiogenic agents to chemotherapy or administering VEGFR TKIs as a single agent has caused more failures than successes. We now have two antiangiogenic agents targeting VEGF pathway that have yielded significant improvement in response rate, PFS, and overall survival (OS) in Phase III trials of patients with advanced NSCLC. In ECOG 4599, bevacizumab, a monoclonal antibody against VEGF, showed an OS benefit in patients with nonsquamous NSCLC when added to carboplatinpaclitaxel first-line chemotherapy. ${ }^{11}$ Ramucirumab is a novel human IgG1 monoclonal antibody that specifically binds to the VEGFR-2 with high affinity, blocking the binding of all VEGF ligands and receptor activation. ${ }^{12}$ The REVEL trial demonstrated that ramucirumab plus docetaxel in secondline treatment of advanced NSCLC produced a significant advantage in terms of response rate, PFS, and OS, without impairment of quality of life. ${ }^{13}$

Apatinib is a novel small-molecule oral agent that strongly and selectively inhibits VEGFR-2 activation. Biologic and preclinical evidence suggests that apatinib effectively blocks proliferation and tube formation of human umbilical vein endothelial cells, and inhibits the growth of xenograft tumors. Interestingly, it also can circumvent cancer cell resistance to chemotherapeutic drugs by directly inhibiting $\mathrm{ABCB} 1$ and ABCG2 function. ${ }^{14}$ A multicenter Phase II study demonstrated that apatinib is active in metastatic breast cancer patients and shows encouraging rates of disease stabilization and PFS..$^{15}$ A Phase III study shows that apatinib, administered as monotherapy, significantly prolonged OS and PFS in patients with advanced gastric cancer experiencing progression after two or more lines of chemotherapy. ${ }^{16}$ An in vitro study revealed apatinib could inhibit the proliferation and metastasis 
of lung cancer cells. ${ }^{17}$ This successful drug is currently being investigated in patients with lung cancer.

Because of the intolerant toxicities of chemotherapy or unsatisfactory therapeutic effect, apatinib was administered after two or more lines of chemotherapy in the three cases mentioned above. Apatinib ( $850 \mathrm{mg} /$ day) was recommended for the treatment of metastatic gastric cancer in a Phase III study, but dose modifications resulting from its toxicity were very common. ${ }^{16}$ In patients with metastatic breast cancer who received apatinib $750 \mathrm{mg}$ /day in a Phase IIa trial, serious adverse events and drug-related deaths occurred. ${ }^{15}$ Therefore, a lower dose of apatinib (500 mg/day) was subsequently administered in the Phase IIb study. Considering the safety issues, the cases mentioned above were treated with apatinib $500 \mathrm{mg} /$ day. The most frequently reported side effects of apatinib were hypertension, proteinuria, and hand-foot syndrome. In our cases, grade 2-3 hypertension and hand-foot skin reaction occurred with a dose of $500 \mathrm{mg} /$ day and they were well managed.

Although the three patients mentioned above who were treated with apatinib achieved PR, patient I's PFS only increased to 2.8 months, which is far less than that in the other two patients. In the ECOG 4599 study, elderly patients did not benefit from treatment with bevacizumab. ${ }^{18}$ Similar to this study, the subgroup of patients of age $\geq 70$ years derived no benefit from therapy with ramucirumab in the REVEL trial. ${ }^{13}$ These results implied that elderly patients could obtain little benefit from antiangiogenic treatments.

Though apatinib did show its effective therapeutic action in NSCLC, especially in advanced lung adenocarcinoma without a driver mutation, it is unclear as to how to select patients who are more likely to be responsive to apatinib. It is hoped that further biomarker analyses will help to screen for appropriate patients with NSCLC.

\section{Acknowledgments}

The authors thank the patients for their participation in the study and agreeing to publish the report.

Written informed consent was obtained from the three patients for publication of this case series and the accompanying images. This case series was approved by the medical ethics committee of the Nanjing Chest Hospital.

\section{Author contributions}

All authors contributed toward data analysis, drafting, and critically revising the paper, gave final approval of the version to be published, and agree to be accountable for all aspects of the work.

\section{Disclosure}

The authors report no conflicts of interest in this work.

\section{References}

1. Jemal A, Siegel R, Ward E, Hao Y, Xu J, Thun MJ. Cancer statistics, 2009. CA Cancer J Clin. 2009;59(4):225-249.

2. Wang S, Cang S, Liu D. Third-generation inhibitors targeting EGFR T790M mutation in advanced non-small cell lung cancer. $J$ Hematol Oncol. 2016;9:34.

3. Wu J, Savooji J, Liu D. Second- and third-generation ALK inhibitors for non-small cell lung cancer. J Hematol Oncol. 2016;9:19.

4. Ma W, Gilligan BM, Yuan J, Li T. Current status and perspectives in translational biomarker research for PD-1/PD-L1 immune checkpoint blockade therapy. J Hematol Oncol. 2016;9(1):47.

5. Xiao HQ, Tian RH, Zhang ZH, Du KQ, Ni YM. Efficacy of pemetrexed plus platinum doublet chemotherapy as first-line treatment for advanced nonsquamous non-small-cell-lung cancer: a systematic review and meta-analysis. OncoTargets Ther. 2016;9:1471-1476.

6. Genova C, Rijavec E, Truini A, et al. Pemetrexed for the treatment of non-small cell lung cancer. Expert Opin Pharmacother. 2013;14(11): $1545-1558$.

7. Ettinger DS, Akerley W, Borghaei H, et al. Non-small cell lung cancer. J National Compr Cancer Netw. 2012;10(10):1236-1271.

8. Hanna N, Shepherd FA, Fossella FV, et al. Randomized phase III trial of pemetrexed versus docetaxel in patients with non-small-cell lung cancer previously treated with chemotherapy. J Clin Oncol. 2004; 22(9):1589-1597.

9. Fossella FV, DeVore R, Kerr RN, et al. Randomized phase III trial of docetaxel versus vinorelbine or ifosfamide in patients with advanced non-small-cell lung cancer previously treated with platinum-containing chemotherapy regimens. The TAX 320 non-small cell lung cancer study group. J Clin Oncol. 2000;18(12):2354-2362.

10. Asahina H, Sekine I, Horinouchi H, et al. Retrospective analysis of third-line and fourth-line chemotherapy for advanced non-small-cell lung cancer. Clin Lung Cancer. 2012;13(1):39-43.

11. Sandler A, Gray R, Perry MC, et al. Paclitaxel-carboplatin alone or with bevacizumab for non-small-cell lung cancer. N Engl J Med. 2006; 355(24):2542-2550.

12. Spratlin JL, Cohen RB, Eadens M, et al. Phase I pharmacologic and biologic study of ramucirumab (IMC-1121B), a fully human immunoglobulin G1 monoclonal antibody targeting the vascular endothelial growth factor receptor-2. J Clin Oncol. 2010;28(5):780-787.

13. Garon EB, Ciuleanu TE, Arrieta O, et al. Ramucirumab plus docetaxel versus placebo plus docetaxel for second-line treatment of stage IV non-small-cell lung cancer after disease progression on platinum-based therapy (REVEL): a multicentre, double-blind, randomised phase 3 trial. Lancet. 2014;384(9944):665-673.

14. Mi YJ, Liang YJ, Huang HB, et al. Apatinib (YN968D1) reverses multidrug resistance by inhibiting the efflux function of multiple ATPbinding cassette transporters. Cancer Res. 2010;70(20):7981-7991.

15. Hu X, Zhang J, Xu B, et al. Multicenter phase II study of apatinib, a novel VEGFR inhibitor in heavily pretreated patients with metastatic triple-negative breast cancer. Int J Cancer. 2014;135(8):1961-1969.

16. Li J, Qin S, Xu J, et al. Randomized, double-blind, placebo-controlled Phase III trial of apatinib in patients with chemotherapy-refractory advanced or metastatic adenocarcinoma of the stomach or gastroesophageal junction. J Clin Oncol. 2016;34(13):1448-1454.

17. Lin C, Wang S, Xie W, Zheng R, Gan Y, Chang J. Apatinib inhibits cellular invasion and migration by fusion kinase KIF5B-RET via suppressing RET/Src signaling pathway. Oncotarget. Epub 2016 Aug 1.

18. Ramalingam SS, Dahlberg SE, Langer CJ, et al. Outcomes for elderly, advanced-stage non small-cell lung cancer patients treated with bevacizumab in combination with carboplatin and paclitaxel: analysis of Eastern Cooperative Oncology Group Trial 4599. J Clin Oncol. 2008;26(1):60-65. 


\section{Publish your work in this journal}

OncoTargets and Therapy is an international, peer-reviewed, open access journal focusing on the pathological basis of all cancers, potential targets for therapy and treatment protocols employed to improve the management of cancer patients. The journal also focuses on the impact of management programs and new therapeutic agents and protocols on

patient perspectives such as quality of life, adherence and satisfaction. The manuscript management system is completely online and includes a very quick and fair peer-review system, which is all easy to use. Visit http://www.dovepress.com/testimonials.php to read real quotes from published authors.

Submit your manuscript here: http://www.dovepress.com/oncotargets-and-therapy-journal 